\title{
Violación e intento de violación de mujeres, patrones de búsqueda de ayuda y denuncia. Un análisis a partir de la ENDIREH 2016
}

\author{
Sonia Frías \\ Universidad Nacional Autónoma de México, México
}

Resumen

Se examina la violación y/o intento de violación de mujeres por parte de una persona distinta a una pareja romántica en tres momentos de la vida: antes de los 15 años, en el último año y a lo largo de la vida a partir de la ENDIREH 2016. Antes de los 15 años, 5.1 por ciento de las mujeres mexicanas han sido violadas o han intentado violarlas. A 7.7 por ciento le ha ocurrido alguna vez en la vida. Las mujeres que hablan una lengua indígena, pobres, urbanas y con baja escolaridad son las más afectadas. En el último año, sólo dos de cada diez mujeres objeto de violación y/o intento de violación buscó ayuda, y sólo $8.4 \%$ de las agresiones sexuales fue objeto de denuncia o queja, no todas ellas ante el Ministerio Público. Se examinan los motivos por los que las mujeres no acuden a buscar ayuda ni interponen denuncia o queja y se discuten las implicaciones de política pública.

Palabras clave: Violación, abuso sexual, México, búsqueda de ayuda, ENDIREH, denuncia.

Abstract

Women's rape and attempted rape, help-seeking behavior and report to authorities. Results from the 2016 ENDIREH

Rape and attempted rape of women during childhood and adolescence (before 15 years old), last year and lifetime by a non-intimate partner are examined by using data from the 2016 National Survey on Household Relationship Dynamics. Before the age of 15 years old, 5.1 per cent of women have experienced rape and/or attempted rape. 7.7 per cent of Mexican women have ever experienced one of them. Women who speak an indigenous language, unprivileged, residing in urban setting and with lower schooling are at a higher risk. During the last 12 months, only two out of every ten women who experienced rape or attempted rape sought help, and less than one out of ten events of rape or attempted rape were reported to law-enforcement agencies. The reasons why women do not seek help and press charges are examined. Public policy implications are discussed.

Keywords: Rape, sexual abuse, Mexico, help-seeking, ENDIREH, police. 


\section{INTRODUCCIÓN}

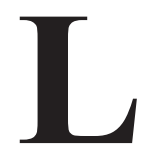

a violación es parte del continuo de violencia sexual del cual son objeto las mujeres (MacKinnon, 1979; Kelly 1987; Kavanaugh, 2012). Desde el acoso en lugares públicos — considerado por muchas personas una forma menor de violencia sexual- a la violación — forma más extrema de la misma—, las mujeres son objeto de múltiples formas de violencia sexual tanto en la esfera pública como en la privada.

Al hablar del continuo de violencia Kelly (1987: 130) se refiere a la incidencia, ya que "hay formas de violencia sexual que padecen la mayoría de las mujeres a lo largo de sus vidas, que también es más probable que sean experimentadas en múltiples ocasiones". En el otro extremo del continuo hay otras formas de violencia que tienen una menor prevalencia como es el caso de la violación o intento de violación. Sin embargo, la normalización y la aceptación de formas menores de violencia sexual contribuye a una cultura de violencia más amplia, que facilita la existencia de un continuo de violencia sexual y excusa la ocurrencia de las manifestaciones más severas, como es la violación (Thirsk 2012; Fileborn 2013).

La violencia sexual en contra de las mujeres, y especialmente la violación es auto silenciada en sociedades que culpabilizan y desacreditan a las mujeres por su propia victimización (Fontes, 2007, Weiss, 2010, Frías y Erviti, 2014). El estudio del fenómeno de la violación, su prevalencia y factores asociados es una tarea compleja (Kruttschnitt et al., 2014), sobre todo en sociedades en que la sexualidad y el sexo tienden a silenciarse y están estigmatizados. En la mayoría de las sociedades familistas y colectivistas, como es el caso de México, las experiencias de abuso sexual tienden a ocultarse (Sabogal et al., 1987; Fontes y Plummer, 2010; Stoltenborgh, 2011).

La violación afecta la salud física y mental de las mujeres, generando problemas como embarazos no deseados, enfermedades de transmisión sexual y VIH, así como consecuencias emocionales que pueden afectar a sus familiares, amigos y redes sociales (Koss et al., 1994; Crowell y Burgess, 1996; Burgess y Carretta, 2016). Muchas de las consecuencias nocivas de una violación pueden prevenirse, reducirse, o al menos controlarse si las víctimas buscan ayuda.

El conocimiento sobre la magnitud del fenómeno de la violación no de pareja entre mujeres mexicanas es limitado, porque las investigaciones publicadas existentes han tendido a centrarse en la violencia de pareja en 
contra de las mujeres, dedicando significativamente menor atención a la violencia sexual y a la violencia que ocurre en contextos de relación distintos a la pareja (Frías, 2014; Frías 2017). La prevalencia de la violencia sexual entre las mujeres mexicanas, y los factores asociados a la misma son inciertos, porque los datos probabilísticos con representación nacional disponibles, hasta la reciente publicación de la Encuesta Nacional sobre la Dinámica de la Relación en los Hogares (ENDIREH) 2016, se encontraban fragmentados y eran inconsistentes.

La reciente ENDIREH 2016, supera varias de las limitaciones de las otras ENDIREH (2003, 2006 y 2011). ${ }^{1}$ Sólo para enumerar algunas, la cantidad de expresiones de violencia sexual medidas, el no ubicar a la persona que responde el cuestionario en un contexto de relación específico en el que se producen los actos constitutivos de victimización sexual, y contemplar el "no lo sé" como opción de respuesta (Frías, 2017). Aunque esto último sólo se incluyó en la ENDIREH 2016 para la medición del abuso sexual acontecido antes de los 15 años.

Al ser la ENDIREH 2016 la mejor fuente disponible y actual para medir la violencia en contra de las mujeres en México, y superar las limitaciones de ediciones anteriores, este estudio examina la prevalencia de la violación e intento de violación por parte de una persona distinta a la pareja antes de los 15 años, a lo largo de la vida y en el último año, identifica a las personas agresoras, los patrones de búsqueda de ayuda de las mujeres, y los motivos por los que no buscaron ayuda.

Concretamente, la primera parte revisa investigaciones previas basadas en encuestas probabilísticas que abordan la violencia sexual hacia las mujeres por parte de personas distintas a la pareja. La segunda parte examina, teóricamente y desde una perspectiva de género, el proceso de afrontamiento y búsqueda de ayuda para las mujeres víctimas de violación. La tercera describe la fuente de datos empleada (ENDIREH 2016), metodología y estrategia analítica. Posteriormente se presentan los resultados, conclusiones, discusión e implicaciones de política pública. Algunos de los datos que se presentan deben interpretarse con cautela, ya que como se indica a lo largo de este trabajo, la violación es un fenómeno con un bajo reporte y con una tasa reducida de denuncias, por lo que la representatividad del análisis estadístico se encuentra condicionada por el número de casos.

${ }_{1}^{1}$ La ENDIREH es una encuesta longitudinal de tendencia que se ha levantado en 2003, 2006, 2011 y 2016. 


\section{LA INVESTIGACIÓN SOBRE VIOLENCIA SEXUAL No DE PAREJa EN MÉXICO}

Aunque en México existen trabajos que abordan el abuso sexual y la violación en el seno de una relación de pareja (Casique, 2006; Oláiz et al., 2006; Oláiz et al., 2009; Casique y Castro, 2012), las investigaciones que abordan la violación por parte de personas distintas a la pareja son escasas (Rivera et al., 2006). Éstas tienden a centrarse en determinados grupos de edad (Chavez Ayala et al., 2009; Frías y Erviti, 2014), o a la experiencia de la violación como explicativa de algún otro fenómeno, como la salud mental o el consumo de drogas (Ramos-Lira et al., 1998; González-Fortaleza et al., 2001; Ramos-Lira et al., 2001).

En México las investigaciones que examinan de una forma cuantitativa las agresiones de carácter sexual en contra de la voluntad de las mujeres, tales como la violación o sexo no consentido son pocas. La prevalencia de violación por parte de alguien distinto a la pareja durante edad adulta oscila entre 1.3 y 6.3 por ciento dependiendo de la encuesta, metodología y población objeto de la misma: Encuesta Nacional sobre Violencia en contra de las Mujeres (ENVIM) 2003 y 2006, Encuesta Nacional de Salud Reproductiva (ENSAR) 2003, Encuesta Nacional sobre la Dinámica de las Relaciones en los Hogares (ENDIREH) 2011 y la Encuesta Nacional de Epidemiología Psiquiátrica (Medina-Mora et al., 2005; Gasman et al., 2006; Rivera et al., 2006; Oláiz et al., 2009; Frías y Ríos, 2017).

Antes de los 15 años, de acuerdo con la ENVIM 2003 y 2006 entre 7.3 y 13.3 por ciento de las mujeres fueron objeto de actos sexuales en contra de su voluntad (Oláiz et al., 2003; Oláiz et al., 2006; Rivera et al., 2006; Oláiz et al., 2009). La Encuesta Nacional sobre Exclusión, Intolerancia y Violencia en Escuelas de Nivel Medio-Superior 2006 y 2009 muestran que entre 1.4 y 1.8 por ciento de las adolescentes fueron objeto de violación antes de cumplir los 18 años (Frías 2012; Frías y Erviti 2014). Otros estudios que emplean la Encuesta Mexicana de Salud Mental Adolescente reportan una prevalencia de dos por ciento (Borges et al., 2008). Antes de los 15 años, los principales agresores tienden a ser personas del núcleo interno de las mujeres como padres, hermanos, etc. (Oláiz et al., 2009).

La diferencia entre las distintas prevalencias sobre la violación reside en la metodología utilizada, la heterogeneidad de las muestras y en la naturaleza de las encuestas. Referido a la naturaleza de las encuestas hay tres grandes grupos de encuestas (ver Walby y Myhill, 2001). En primer lugar, las encuestas generales sobre victimización, como la Encuesta Nacional 
de Victimización Percepción sobre Seguridad Pública (ENVIPE) (20112016), buscan medir incidencia delictiva, el nivel de reporte de victimización a las autoridades públicas, así como la percepción de inseguridad. No obstante, no fueron originalmente diseñadas para abordar la problemática de la violencia hacia las mujeres, ya que se centran en delitos y no en victimización y los reactivos para medir la problemática son muy reducidos. El segundo grupo está conformado por las encuestas sobre violencia doméstica. Éstas tienden reducir la tensión generada al entrevistado al no referirse a crimen ni victimización y tienden proporcionar una mejor estimación de las prevalencias. Sin embargo, al centrarse en la dinámica familiar dejan sin explorar la violencia acontecida en otros ámbitos. Finalmente, las encuestas generales sobre violencia en contra de las mujeres tienen por objeto medir las distintas formas de violencia hacia las mujeres en distintos contextos. Éstas tienden a proporcionar los mayores porcentajes de agresiones perpetradas en contra de las mujeres (sean estas constitutivas de delitos o no). Por ejemplo, menos de uno por ciento de las mujeres que contestaron la ENVIPE 2016 indicaron que en el último año "alguien en contra de su voluntad la agredió mediante hostigamiento sexual (sic.), manoseo, exhibicionismo o intento de violación", en cambio la ENDIREH 2016 muestra que sólo en el ámbito comunitario (espacios o lugares públicos) 5.2 por ciento de las mujeres indicaron que en el último año las habían "manoseado, tocado, besado, arrimado, recargado o encimado sin su consentimiento" (cálculos propios).

De forma adicional a la naturaleza de la encuesta, existen otros factores que pueden estar detrás de la inconsistencia entre las cifras: la forma en que se realiza la entrevista o aplicación el cuestionario, la confidencialidad, la preparación del entrevistador/a, la similitud de características entre el entrevistador/a y el entrevistado/a, el marco muestral, la forma en que se aplica la entrevista, la operacionalización de las definiciones y la contextualización del evento con respecto a otros eventos (Walby y Myhill, 2001; Kubiak et al., 2012).

\section{El PROCESO DE AFRONTAMIENTO DEL PROBLEMA Y LA BÚSQUEDA de AYUdA. CoMprendiendo EL PROCESO DESDE}

\section{UNA PERSPECTIVA DE GÉNERO}

En el imaginario social, las mujeres que son víctimas de violencia son vistas como seres pasivos e indefensos, que sobrellevan y aguantan la violencia que padecen. Sin embargo, distintas fuentes empíricas muestran que esta imagen no es aplicable a todas las mujeres, ya que dependiendo del 
tipo de violencia y del ámbito en el que ésta se produce - familiar, educativo, laboral, comunitario, institucional o de pareja - las mujeres hacen frente a la violencia y han desarrollado diversas estrategias para superar las situaciones y salir adelante (Castro y Erviti, 2003; Hay, 2005; Gaytan Sánchez, 2009; Fanslow y Robinson, 2010; Barrett y St. Pierre, 2011; Douglas y Hines, 2011; Zakar et al., 2012; Frías, 2013; Frías, 2013; Frías y Agoff, 2015).

El proceso dinámico por el cual transitan las mujeres para hacer frente a su victimización (coping en inglés), es complejo. Finn (citado en Zakar et al., 2012) argumenta que existen estrategias pasivas y activas para hacer frente a las situaciones de violencia. Los esfuerzos emocionales y, aparentemente, no observables para lidiar con situaciones adversas, se catalogan como estrategias pasivas. En cambio, los esfuerzos observables y conductuales para enfrentar estas situaciones son parte de las estrategias activas.

Otros autores hablan de estrategias de afrontamiento evasivas vs. activas, o bien, de cognitivas/emocionales vs. conductuales. De acuerdo con la revisión de Zakar et al. (2012) las estrategias pasivas, evasivas, emocionales y de desvinculación se describen como un afrontamiento que se traduce en la evasión o negación de una realidad desagradable. En cambio, las estrategias de enfrentamiento activas, comprometidas y que conllevan cambios conductuales, tienden a abordar las verdaderas causas del problema. Las primeras también se conocen como estrategias de afrontamiento basadas en las emociones, ya que a partir de la modificación de las emociones se trata de superar la situación. Las segundas se encuentran centradas en la solución del problema al utilizar estrategias centradas en las causas asociadas al problema asociado a la violencia. Estas últimas son "más realistas y más útiles para encontrar una solución, así como para eliminar o reducir las causas subyacentes al estrés" (Zakar et al., 2012: 3270).

Las mujeres objeto de violencia pueden adoptar, tanto estrategias basadas en las emociones, como estrategias centradas en el problema. En algunas ocasiones no precisan de ayuda externa para hacer frente a la situación de violencia, pero en otras ocasiones precisan de apoyo externo. Con independencia de la estrategia de afrontamiento desarrollada por las mujeres y de si precisan apoyo externo o no, las víctimas de violencia pasan por distintas fases antes de recibir (si es que así lo deciden) apoyo y hacer frente a la violencia: i) reconocimiento y definición del problema; ii) decisión de pedir ayuda y, finalmente; iii) la selección de la fuente de ayuda (Liang et al., 2005). En todas estas fases intervienen diversos factores individuales, contextuales, y sociales (Kaukinen, 2002; Kogan, 2004; Menard, 2005) 
La primera fase consiste en el reconocimiento del problema. Es decir, la persona debe percibir su victimización como una injusticia y sentir que han violado sus derechos. Sin embargo, no todas las agresiones son conceptualizadas como tal por el individuo. En el caso de la violación, es importante tener en cuenta los significados culturales atribuidos a ésta, ya que dependiendo de la interpretación que se haga de la experiencia, se transitará o no por las distintas fases del modelo de búsqueda de ayuda. Los significados atribuidos por las víctimas a un mismo evento - la violación - varían de cultura en cultura. Los actos que son considerados como violación o abuso sexual en una cultura o contexto son ignorados o condonados en otras (Ramos-Lira et al., 1999; Fontes y Plummer, 2010).

Investigaciones realizadas en otros países muestran que algunas víctimas no conceptualizan sus experiencias como una violación a sus derechos (Kahn et al., 2003; Fisher, 2009). Se ha estimado que entre 42 y 78 por ciento de las víctimas de violación no catalogan su experiencia como violación o consideran que fue resultado de una grave confusión (ver LeMaire et al., 2016). Estas personas es probable que no respondan afirmativamente a las preguntas de un cuestionario, acudan a buscar ayuda o que no reporten el evento a las autoridades. Kahn y cols. (2003) señalan que las mujeres que tienden a reconocer sus experiencias como una violación tienden a ser de mayor edad, no conocían a su agresor o lo conocían poco, la forma en que se produjo la violación fue más violenta y tuvieron reacciones emocionales más severas tras su experiencia. En cambio, cuando el agresor es su pareja, cuando la mujer estaba bajo el efecto de las drogas o el alcohol, o bien, si el acto implicó sexo oral o digital, las mujeres catalogaron en menor medida su experiencia como una violación. Peterson y Muehlenhard (2011) encontraron que las mujeres que catalogan en menor medida su experiencia como violación son aquellas que consideran que no se resistieron suficientemente, que el evento no fue lo suficientemente violento o forzado, o fueron parcialmente responsables por su propio comportamiento (ej. decir que no en el último momento). Las actitudes, creencias y valores de las mujeres como la aceptación de mitos sobre violación o la tolerancia hacia el acoso sexual está asociado de forma negativa a que una experiencia de violación se catalogue como tal (LeMaire et al., 2016).

El proceso de búsqueda de ayuda inicia una vez que las mujeres definen un determinado acto o conducta como constitutivo de violencia $\mathrm{y}$, como consecuencia, lo etiquetan como algo inaceptable. Una vez que identifican el problema y desarrollan un sentimiento de indignación y rabia, el siguiente paso es decidir si van a pedir ayuda o no. El pedir ayuda, ya sea 
en instancias formales o informales conlleva a revelar que fueron objeto de abuso sexual. Los sentimientos de vergüenza y culpabilidad socialmente construidos (Fontes y Plummer, 2010; Weiss, 2010), el miedo, así como baja autoestima, pueden socavar la intención de buscar algún tipo de ayuda. Las mujeres sienten que van a defraudar a la familia, y en ocasiones no saben cómo ésta va a reaccionar (Ramos-Lira et al., 1999; Fontes y Plummer, 2010).

La tercera fase del modelo teórico de Liang et al. (2005) consiste en la selección de un proveedor de ayuda. Esta selección depende de varios factores, como quién(es) cree la mujer que le proporcionará ayuda y que ésta cubra sus expectativas. Otros factores que intervienen son su deseo de privacidad, potencial estigmatización y la severidad de la violencia. La disponibilidad de redes de apoyo familiares, el conocimiento de fuentes formales de apoyo y disponer de los recursos suficientes para acceder a éstas últimas, determinan dónde la persona busca ayuda (Rose et al., 2000; Sabina, 2011).

Dependiendo de la disponibilidad y conocimiento, las mujeres pueden acudir a fuentes de apoyo informales o formales. Las fuentes informales de apoyo están conformadas, entre otros, por amistades, familiares, conocidos y líderes espirituales. Las fuentes formales son instituciones públicas (policía, agencias de prevención y atención), privadas (médicos o psicólogos), o bien, organizaciones sin ánimo de lucro, como pueden ser organizaciones de la sociedad civil. Investigaciones realizadas en Canadá muestran que dependiendo de quién sea el responsable de la violación, es más probable que las mujeres acudan a fuentes informales de apoyo como amigos y familiares (Kaukinen, 2002). Las víctimas de violaciones que cumplen con el estereotipo de violación y las que han padecido lesiones es más probable que acudan a la policía o servicios de salud (Ullman y Filipas, 2001; Fisher et al., 2003). Otros factores como los gastos que la mujer debe incurrir para buscar ayuda, así como la distancia y el tiempo requerido también incide en la selección de un proveedor de ayuda (Muganyizi et al., 2011).

Asimismo, el pedir ayuda a fuentes formales no implica que las mujeres sigan todo el proceso previsto por las instancias que brindan ayuda (Murphy et al., 2014), ni que reciban la atención requerida. Esto último sobre todo en los servicios de salud y de procuración de justicia, los cuales - en el contexto mexicano - son centrales para garantizar su acceso a la justicia (Frías y Ríos, 2017). Las agencias de procuración e impartición de justicia tienden a reproducir las normas, estereotipos y jerarquías de género imperantes en la sociedad (MacKinnon, 1989) y en el caso de México suelen 
carecer de la capacidad institucional para proporcionar servicios. El personal de las agencias de procuración e impartición de justicia suelen tener falsas creencias sobre las víctimas de violación (Fernández Rodríguez de Liévana, 2015), y no suele catalogar como violaciones aquellas perpetradas por conocidos o pares de la víctima o cuando se ha producido consumo de alcohol (Campbell, 1998). Además, con frecuencia estigmatizan a la víctima y la culpabilizan de su propia victimización (Maier, 2008; Rich y Seffrin, 2012; Frías, 2013). La orientación sexual de las víctimas, así como su posición en los sistemas de estratificación social también influye en que las mujeres tengan acceso a servicios de justicia y salud (Phipps, 2009; McNair y Neville, 2010).

Los pocos estudios que examinan los procesos de búsqueda de ayuda formal tras una violación perpetrada por alguien distinto a la pareja en México tienden a estar centrados en abusos sexuales durante adolescencia e infancia (Chavez Ayala et al., 2009; Frías y Erviti, 2014). Estos muestran que la mayoría de los delitos sexuales, incluyendo la violación tienden a no denunciarse. El estigma, el deseo de privacidad y la construcción genérica de la sexualidad femenina son algunos de los factores que generan la falta de denuncia y el silencio alrededor de estas experiencias (Frías y Erviti, 2014). Entre mujeres adultas, la ENDIREH 2011 mostró que sólo 19.1 por ciento de las mujeres violadas en el último año por alguien distinto a la pareja (18 de cada 10 mil) buscó ayuda formal en instituciones públicas (Frías y Ríos, 2017). Las mujeres acudieron principalmente a agencias de procuración de justicia ( 8.4 por ciento) y la policía (seis por ciento).

\section{Métodos Y eSTRATEgia ANALÍtica}

Para contribuir a llenar los vacíos en el conocimiento del fenómeno de la violación sexual de mujeres por personas distintas a su pareja, así como arrojar luz sobre sus patrones de búsqueda de ayuda, se utiliza la cuarta ENDIREH. Esta encuesta, realizada en 2016, fue iniciativa del Instituto Nacional de Geografía, Estadística e Informática (INEGI) y el Instituto Nacional de las Mujeres (INMUJERES), y es representativa de todas las mujeres mexicanas de 15 años o más con independencia de su situación conyugal. A pesar de sus limitaciones, es un instrumento que proporciona información valiosa sobre las experiencias de las mujeres mexicanas en torno a una violación.

La medición de la violación y el intento antes de los 15 años se realiza a partir de la respuesta afirmativa a cualquiera de los dos reactivos: "¿La obligaron a tener relaciones sexuales bajo amenazas o usando la fuerza?” 
y “¿Intentaron forzarla a tener relaciones sexuales?” 2.88 por ciento de las mujeres (aproximadamente un millón 250 mil mujeres) respondieron afirmativamente a la primera pregunta y 4.3 por ciento a la segunda (aproximadamente un millón 183 mil mujeres). En total 5.06 por ciento de las mujeres indicó que la habían violado y/o habían intentado hacerlo (dos millones 290 mil). 62 por ciento de las mujeres que reportaron que la habían intentado violar antes de los 15 años indicó que la habían violado, aunque no se sabe si está haciendo referencia al mismo evento o no. Un porcentaje considerable de mujeres (casi seis por ciento) reportó no recordar si había sido objeto de este tipo de situaciones antes de la edad de 15 años. Esto equivale aproximadamente a dos millones 600 mil mujeres. Se desconoce si padecieron la situación y no la desearon reportar, si la situación generó una pérdida de memoria del evento, o si verdaderamente no recuerdan si el evento ocurrió. El porcentaje de mujeres que no recuerdan fluctúa entre 4.4 por ciento y cinco por ciento entre las mujeres de 40 años o menos, y es superior a 7.3 por ciento entre las mujeres mayores de 60 años.

Después de los 15 años, una mujer es considerada como víctima de violación si reportó que había sido obligada a tener relaciones sexuales en contra de su voluntad durante el periodo de referencia (a lo largo de su vida o/y en los últimos doce meses). ${ }^{2}$ De forma semejante el intento de violación consiste en si indicó que alguien trató de obligarla a tener relaciones sexuales en contra de su voluntad en esos periodos de referencia. A diferencia de la victimización sexual antes de los 15 años, para la victimización sexual acontecida después de los 15 años, no existe la opción de respuesta "no lo sé, no recuerdo".

La ENDIREH 2016 también indagó sobre la edad que tenía la mujer cuando tuvo la primera relación sexual, y si esa experiencia fue con consentimiento o porque usted así lo quiso o sin consentimiento, tres por ciento de las mujeres indicó que su primera relación sexual no había sido consentida. De éstas, 63.9 por ciento respondió afirmativamente a las preguntas para identificar violación en distintos contextos de relación. El resto, 36.1 por ciento no respondió positivamente a éstas. Estos casos fueron recodificados $(n=1090)$. La recodificación tuvo en cuenta la edad en que la mujer indicó que ocurrió el evento, para clasificarlas como objeto de violación antes o después de los 15 años. En el caso de que la mujer no hubiera proporcionado información sobre la edad en que aconteció el evento, se imputó en la prevalencia global de violación. En estos casos, no se pudo

\footnotetext{
${ }^{2}$ Esta variable se construyó con las respuestas de cuatro secciones que miden la victimización en los siguientes ámbitos: escolar, laboral, comunitario, familiar.
} 
realizar el análisis subsecuente sobre relación con la persona agresora, búsqueda de ayuda, denuncia, etc.

Con respecto a la búsqueda de ayuda, la ENDIREH 2016 indaga sobre si las mujeres objeto de alguna forma de violencia - durante el año anterior al levantamiento de la encuesta y a lo largo de la vida - le contaron a alguien, y si pidieron apoyo, información o servicios en alguna dependencia pública o de gobierno, o algún grupo o asociación no gubernamental y privada. Además, explora si la mujer o alguien de su familia presentó alguna queja o denunció lo ocurrido ante alguna autoridad (autoridades de su trabajo o del sindicato, policía, autoridades municipales o delegacionales, Ministerio Público y Procuraduría — federal o local— de la Defensa del Trabajo.

Con respecto a las variables sociodemográficas y de violencia asociadas a la experiencia de violación y/o intento de violación, el proceso de búsqueda de ayuda y denuncia, situación conyugal es una variable con tres categorías: casada o unida; separada, divorciada o viuda y; soltera. Edad es una variable continua que indica el número de años cumplidos de la mujer. Estrato socioeconómico es una variable que mide el estrato socioeconómico de pertenencia de la mujer en función del promedio de años de educación de los integrantes del hogar, el estatus ocupacional del/a integrante del hogar con mayor potencialidad de ingreso basado en el promedio para esa ocupación, y finalmente los bienes y condiciones del hogar, como por ejemplo disponibilidad de agua y electricidad, cocina, etc. Esta variable que tiene cuatro categorías (muy bajo, bajo, medio y alto) fue calculada por Echarri, basada en la metodología que él mismo desarrollo para otras ENDIREH (Echarri, 2008). Nivel de escolaridad es una variable que clasifica el nivel de escolaridad completado por la mujer en seis categorías: sin escolaridad, primaria, secundaria, bachillerato o equivalente, estudios técnicos o escuela normal, y universitaria. Empleada y asiste a la escuela son variables dicotómicas codificadas como 1 cuando la mujer trabajó a cambio de un pago la semana anterior o fue a la escuela, y 0 cuando no lo hizo. Índice de roles de género, es una medida desarrollada por Casique (Casique y Castro, 2014), y calculada por ella misma, que evalúa la opinión sobre los roles masculinos y femeninos.

Con respecto a las variables contextuales, ámbito de residencia clasifica la localidad en que reside la mujer en rural o urbana. Reside con sus padres se codifica como 1 cuando la mujer reside en su hogar de procreación y 0 cuando no. Número de personas en el hogar es una variable continua que indica cuántas personas comparten el hogar con la mujer. Fortaleza de 
redes sociales es una variable continua que evalúa con cuántas personas cuentan las mujeres para: i) cuidar a sus hijos cuando tienen alguna emergencia o se enferman; ii) hacer alguna tarea o labor; iii) cuando la mujer se enferma; iv) para platicar de sus problemas o preocupaciones; v) para que le den consejos u orientación cuando tiene dificultades con su esposo o pareja, y; e) cuando tiene alguna dificultad o problema económico (Cronbach Alpha $=0.71)$.

La estrategia analítica se realiza en cinco pasos: i) análisis descriptivo de la prevalencia de violación y/o intento de violación no de pareja según el contexto de relación y temporalidad; ii) análisis descriptivo de las personas responsables de la violación e intento de violación; iii) análisis bivariado con pruebas de diferencias estadísticas de las principales variables sociodemográficas y contextuales asociadas a la violación y/o intento de violación; iv) análisis bivariado de los patrones de búsqueda de ayuda de las mujeres objeto de violación o intento de violación y análisis de regresión logística multivariada de las variables asociadas a la búsqueda de ayuda por violación o intento de violación en el último año y denuncia durante ese mismo periodo de tiempo. Finalmente, v) análisis descriptivo de los motivos por los que las mujeres no acuden a buscar ayuda ni interponen denuncia según contexto de relación en que ocurre la violación y/o intento de violación.

\section{LAS EXPERIENCIAS DE VIOLACIÓN Y/O INTENTO DE VIOLACIÓN NO DE PAREJA ENTRE LAS MUJERES MEXICANAS}

De acuerdo con los datos de la ENDIREH 2016 examinados en la Tabla 1, antes de los 15 años, 5.06 por ciento de las mujeres mexicanas reportaron haber padecido un intento de violación (4.3 por ciento) y/o haber sido violada o forzada a tener relaciones sexuales bajo amenazas o uso de la fuerza (2.88 por ciento).

Después de los 15 años, las mujeres también son objeto de violaciones e intentos de violación. En la Tabla 1 se presentan la prevalencia de violación e intentos de violación tanto a lo largo de la vida, como en los últimos 12 meses en función del contexto de relación en que se produjo. Los datos muestran que a 11 de cada mil mujeres que han trabajado alguna vez en su vida, intentaron violarla en el trabajo, y a casi cuatro de cada mil la violaron en el trabajo. Las instituciones educativas también son un espacio peligroso para las mujeres ya que a casi siete de cada mil mujeres que alguna vez ha asistido a la escuela han intentado violarla, y a casi tres de cada mil la violaron. En el contexto público, comunitario, o de ausencia de 
relación laboral, educativa, familiar y de pareja (Frías, 2017), a 13 de cada mil mujeres intentaron violarla y a seis de cada mil la violaron. Estas cifras sugieren que al menos a 30 de cada mil mujeres ( 3.1 por ciento) la han violado o intentado violar después de los 15 años en alguna ocasión alguna persona diferente a una pareja. Si además tenemos en cuenta los casos en que las mujeres reportaron que su primera relación sexual no fue consentida, el porcentaje después de los 15 años se incrementa a 4.16 por ciento.

La Tabla 1 también examina la prevalencia de violación y/o intento de violación en el último año. 3.6 de cada mil mujeres fue objeto de alguna de estas conductas en el ámbito público o contexto comunitario; 3.8 de cada mil en el trabajo; 2.8 de cada mil en la escuela y 4.7 mujeres de cada mil en su familia. En total, casi una de cada cien mujeres (0.978) fue objeto de violación o intento de violación no de pareja en el último año. Esto equivale aproximadamente a 475 mil mujeres.

Tabla 1: Prevalencia de violación y/o intento de violación no de pareja, según contexto de relación y temporalidad (en porcentajes)

\begin{tabular}{|c|c|c|c|}
\hline & $\begin{array}{r}\text { Intentaron } \\
\text { orzarla a tener } \\
\text { relaciones } \\
\text { sexuales } \\
\end{array}$ & $\begin{array}{r}\text { La obligaron a tener } \\
\text { relaciones sexuales bajo } \\
\text { amenazas o usando la } \\
\text { fuerza }\end{array}$ & $\begin{array}{r}\text { Intento de } \\
\text { violación y/o } \\
\text { violación }\end{array}$ \\
\hline Antes de los 15 años & 4.30 & 2.88 & 5.06 \\
\hline \multicolumn{4}{|l|}{ Después de los 15 años } \\
\hline Comunitario & 1.32 & 0.60 & 1.41 \\
\hline Laboral & 1.14 & 0.36 & 1.22 \\
\hline Escolar & 0.67 & 0.27 & 0.77 \\
\hline Familiar (12 meses) ${ }^{*}$ & 0.39 & 0.30 & 0.47 \\
\hline Cualquiera & 2.75 & 1.26 & 3.06 \\
\hline $\begin{array}{l}\text { Ajuste primera relación sexual } \\
\text { no consentida }\end{array}$ & & 2.43 & 4.16 \\
\hline \multicolumn{4}{|l|}{ Último año } \\
\hline Comunitario & 0.33 & 0.14 & 0.36 \\
\hline Laboral & 0.37 & 0.12 & 0.38 \\
\hline Escolar ${ }^{*}$ & 0.28 & 0.12 & 0.28 \\
\hline Familiar & 0.39 & 0.30 & 0.47 \\
\hline Cualquiera & 0.85 & 0.48 & 0.97 \\
\hline Alguna vez en su vida & 5.94 & 4.39 & 7.77 \\
\hline
\end{tabular}


Los datos sobre prevalencia de ambas formas de victimización alguna vez en la vida en la última línea de la Tabla 1 muestran que a casi seis de cada cien mujeres mexicanas han intentado violarla, y que a 4.4 por ciento de las mujeres las han violado. En total 7.8 por ciento de las mujeres mexicanas han sido objeto de violación o de intento de violación a lo largo de nuestra vida.

\section{LOS PERPETRADORES DE LAS VIOLACIONES E INTENTOS DE VIOLACIÓN NO DE PAREJA}

La Tabla 2 examina quién(es) fueron las personas agresoras. Los porcentajes de columna no suman 100 por ciento porque las mujeres fueron victimizadas por más de una persona distinta, aunque la ENDIREH 2016 no permite distinguir si fue en la misma o distinta ocasión. La mayor parte de las violaciones intentos de violación antes de los 15 años se producen por personas del círculo familiar de las mujeres. Alrededor de seis por ciento de los casos son los padres, aproximadamente una de cada diez mujeres indicó que había sido su hermano/a. Destaca que los tíos/as y primos/as sean la categoría más numerosa, (respectivamente, 28.6 y 38.5 por ciento). Los desconocidos fueron señalados como responsables en un menor porcentaje de casos (13.2 por ciento de los intentos de violación y 10.3 por ciento de las violaciones consumadas). 22.7 por ciento de las mujeres objeto de violación indica que fue otra persona. Aunque esta respuesta puede referirse a que no identificaron a la persona entre las categorías de respuesta, también puede sugerir que las mujeres no deseaban identificar a la persona agresora.

Después de los 15 años, en el ámbito público o comunitario, las mujeres reportan que las personas que intentaron violarlas o que lo lograron a lo largo de su vida eran en su mayoría desconocidos (respectivamente, $49.1 \mathrm{y}$ 43.8 por ciento). Personas conocidas por las mujeres perpetraron 37.4 por ciento de las violaciones y 30.5 por ciento de los intentos de violación. 18.5 por ciento de las mujeres violadas señaló como responsable a un amigo o vecino. Destaca, asimismo, que 2.3 por ciento de las mujeres violadas en el ámbito público o comunitario indicara que lo fue por parte de un policía o militar, y uno por ciento por parte de un sacerdote. Finalmente, 4.8 por ciento de las mujeres indicó que había sido violada por otra persona (se incluyen los conductores de transporte público). 
Violación e intento de violación de mujeres, patrones de búsqueda de ayuda y denuncia. Un análisis a partir ... /S. FRÍAS

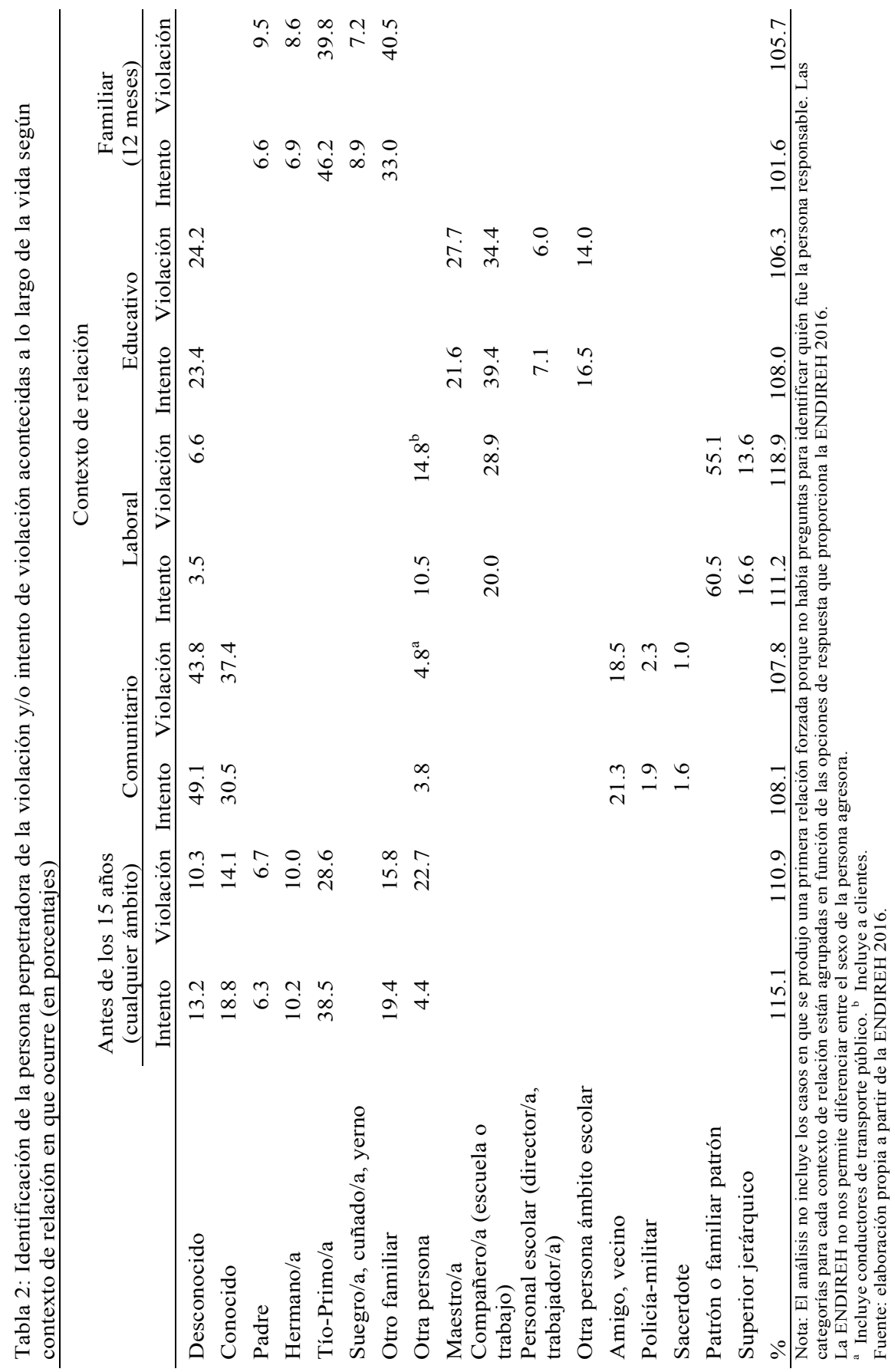


La tercera sección de la Tabla 2 se centra en la violación e intento de violación en un contexto de relación laboral. Los datos muestran que más de la mitad de las violaciones y e intentos de violación fueron perpetrados por personas con quien la mujer tenía una relación jerárquica (patrones o familiares de patrones, y superiores jerárquicos). En menor medida señalaron a compañeros de trabajo (28.9 por ciento de las violaciones y 20 por ciento de los intentos de violación). Una de cada diez mujeres señaló a otra persona como responsable, lo cual incluye a clientes.

En el contexto de una relación educativa, los principales perpetradores de las violaciones e intentos son los pares (respectivamente, 34.4 y 39.4 por ciento), seguido de maestros (27.7 y 21.6 por ciento). El personal no docente de la escuela fue señalado en seis por ciento de los casos. Destaca que las personas desconocidas sean quienes perpetran alrededor de una de cada cuatro violaciones e intentos de violación (24.2 y 23.4 por ciento).

Finalmente, en el contexto de una relación familiar, cuatro de cada diez mujeres violadas en el último año responsabilizaron a un primo/a o tío/a. Éstos también fueron quienes perpetraron 46.2 por ciento de los intentos de violación. Los padres y hermanos, cuñados, suegros y yernos emergen como responsables en menor medida. Tal y como sucede en el caso de la violación e intento de violación antes de los 15 años, un porcentaje considerable de las mujeres (al menos una de cada tres) responsabilizó a otro familiar.

\section{LOS FACTORES ASOCIADOS A LA EXPERIENCIA DE VIOLACIÓN O INTENTO dE VIOLACIÓN NO DE PAREJA}

La Tabla 3 examina de forma bivariada las principales variables sociodemográficas asociadas a haber sido objeto de una violación o intento de violación en los últimos 12 meses y alguna vez en la vida. La primera columna se centra en las experiencias acontecidas durante el último año. En este periodo las mujeres que no tienen pareja reportan mayores niveles que las casadas o unidas. Por ejemplo 14.2 de cada mil mujeres solteras indicó que había sido violada o padecido un intento comparado con 8.3 de cada mil casadas o unidas. Las mujeres de estrato socioeconómico alto reportan significativamente menores niveles de violación y/o intento de violación en el último año que las mujeres de otros estratos socioeconómicos (no hay diferencias estadísticamente significativas entre las mujeres de estrato muy bajo, bajo y medio). Las mujeres con nivel de escolaridad de secundaria y bachillerato o equivalente reportan en mayor medida haber sido violadas y/o sufrido un intento que las mujeres con otros niveles de escolaridad. 
Tabla 3: Análisis bivariado de las principales variables sociodemográficas y contextuales asociadas a la experiencia de violación y/o intento de violación en los últimos 12 meses y alguna vez en la vida (porcentajes y medias)

Características sociodemográficas 12 Meses Alguna vez en la vida Edad

$* * *$

No

Desviación estándar

Sí

Desviación estándar

Situación conyugal

Casada o unida

Separada, divorciada, viuda

Soltera

Estrato socioeconómico

Muy bajo

Bajo

Medio

Alto

Habla una lengua indígena

No

Sí

Nivel de escolaridad

Sin escolaridad

Primaria

Secundaria

Bachillerato, estudios técnicos

Estudios técnicos o normal

Universitaria

Empleada

No

Sí

Asiste a la escuela

No

Sí

Características contextuales

Ámbito de residencia

Rural

Urbano

Núm. personas en el hogar

No

Desviación estándar

Sí

Desviación estándar

Mujer reside con sus padres

No

Sí

Experiencias previas de violencia

Violación o intento antes de 15 años

No

Sí

$* * * \mathrm{p}<0.0001$

Fuente: elaboración propia a partir de la ENDIREH 2016.
41.3

16.9

35.0

14.0

$* * *$

0.8

1.1

1.4

$* * *$

0.9

1.1

1.0

0.7

1.0

0.9

$* * *$

0.8

0.8

1.2

1.2

0.9

0.8

$* * *$

0.9

1.2

***

0.9

1.4

***

0.8

1.0

4.3

1.9

4.3

1.9

$* * *$

0.9

1.4

***

0.6

7.3
$* * *$

41.1

16.9

42.4

15.7

$* * *$

7.5

10.7

5.7

***

8.0

8.7

7.3

6.3

***

7.7

9.5

***

10.2

8.4

8.4

6.6

7.2

6.0

***

6.9

9.2

***

8.0

5.6

***

6.7

8.1 $* * *$

4.3

1.9

4.3

1.9

***

8.1

6.2 
Las mujeres urbanas, empleadas, que asisten a la escuela y que residen con sus padres reportan significativamente mayores niveles de violación e intento de violación que sus homólogas rurales, desempleadas, que no asisten a la escuela y que no residen con sus progenitores. La condición de hablante de lengua indígena y el número de persona en el hogar no discrimina entre las mujeres que experimentaron violación y/o intento de violación y las que no durante el último año. Finalmente, las experiencias previas de violación y/o intento, están fuertemente asociadas a padecerlo de nuevo en el último año: 7.34 por ciento de las mujeres víctimas antes de los 15 años lo padecieron de nuevo en el último año, comparado con 0.64 por ciento de las mujeres que no lo experimentaron.

La segunda parte de la Tabla 3 muestra las características actuales de las mujeres que han sido objeto de violación y/o de un intento de violación a lo largo de su vida. Estas variables no corresponden - como en el caso de la primera columna - al momento en que se produjeron el/los eventos/s. Los análisis bivariados muestran que una de cada diez mujeres que alguna vez estuvieron unidas, pero que no lo están actualmente fueron violadas o padecieron un intento de violación. Cifra que contrasta con las mujeres casadas o unidas ( 7.5 por ciento) o solteras (5.7 por ciento). Esta cifra puede estar vinculada con la menor edad de las solteras y consecuente menor tiempo de exposición al riesgo.

Las mujeres de estratos socioeconómicos más desfavorecidos reportan en mayor medida la/s experiencia/s , así como las mujeres urbanas, las empleadas, las que hablan una lengua indígena, las que no asisten a la escuela en la actualidad, y las que viven con sus padres. Esto puede ser relacionado, como en el modelo anterior, con la menor edad de las mujeres y menor exposición al riesgo. En general, una de cada diez mujeres sin escolaridad indicó que había padecido al menos una violación o un intento de violación a lo largo de su vida. Este dato contrasta con las experiencias reportadas de mujeres universitarias (seis por ciento).

\section{LA BÚSQUEDA DE AYUdA DE LAS MUJERES OBJETO DE VIOLACIÓN Y /O INTENTO DE VIOLACIÓN}

La ENDIREH 2016 permite examinar los patrones de búsqueda de ayuda en caso de violación y/o intento y si las mujeres víctimas comentaron su victimización con alguien. Los datos presentados en la Tabla 4 muestran que las experiencias se viven en silencio por una cantidad considerable de mujeres. 
Violación e intento de violación de mujeres, patrones de búsqueda de ayuda y denuncia. Un análisis a partit ... /S. FRÍAS

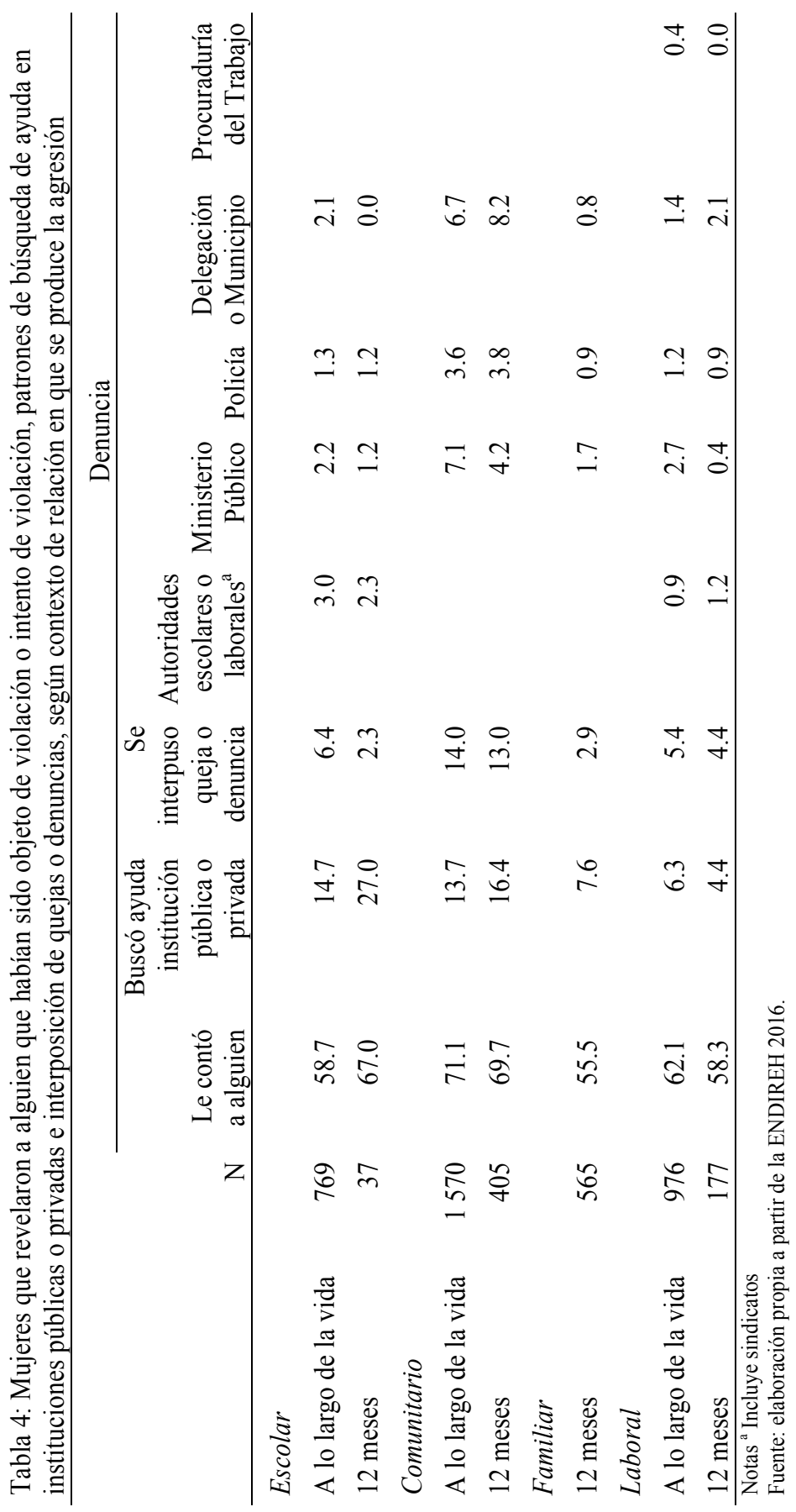


Que le cuenten o no a alguien parece estar asociado al contexto de relación en que se produce el evento. Las experiencias de violación y/o de intento de violación en el ámbito público o comunitario a lo largo de la vida tienden a ser reveladas en mayor medida a otras personas (71.1 por ciento) que las acontecidas en el contexto laboral (62 por ciento) o escolar (58.7 por ciento). Lo mismo sucede con aquellas ocurridas durante el año: las mujeres reportaron en mayor medida haber contado a alguien sobre el suceso cuando este ocurrió en el ámbito comunitario y escolar (69.7 y 67 por ciento), que cuando sucedió en un contexto de relación laboral y familiar (58.3 y 55.2 por ciento).

Los porcentajes de búsqueda de ayuda en instituciones públicas son mucho más reducidos. Sólo entre 6.3 y 14.7 por ciento de las mujeres violadas y/o que padecieron un intento a lo largo de su vida buscaron ayuda en alguna institución pública o privada. La búsqueda de ayuda es contingente al contexto de relación entre la persona agresora y la víctima: alrededor de 14 por ciento de las que lo padecieron en un contexto de relación escolar o comunitario/público buscaron ayuda formal, comparado con 4.4 por ciento de mujeres a quienes les ocurrió en el trabajo. Los datos muestran un patrón temporal relevante, ya que la búsqueda de ayuda en el último año es mayor que a lo largo de la vida, con excepción del contexto de relación laboral.

Que las mujeres comuniquen su victimización a alguien y que acudan a buscar ayuda, no quiere decir que se interpongan denuncias o quejas por los eventos de violación o intento de violación. Sólo 14 por ciento de las mujeres objeto de violación o de intento de violación en el espacio público o comunitario a lo largo de su vida interpusieron una queja o denuncia. El porcentaje cae a menos de la mitad en el contexto escolar (6.4 por ciento) y en el laboral (5.4 por ciento). Con respecto a los eventos durante el último año, las violaciones y/o intentos de violación por las que se interponen más quejas o denuncias son ocurridas en el contexto público o comunitario (13 por ciento). Por las que menos se interponen son cuando la persona perpetradora es un familiar (2.9 por ciento).

Finalmente, la Tabla 4 nos permite conocer la institución ante la cual se interpone la denuncia o queja. Los datos muestran que las mujeres tienden a acudir en mayor medida a las agencias de procuración de justicia. Sin embargo, las cifras que arroja la ENDIREH 2016 muestran un panorama desolador con respecto al acceso a la justicia de las víctimas. Por ejemplo, sólo 4.2 por ciento de las violaciones o intentos de violación acontecidos en el espacio público durante el último año fueron denunciados ante el 
Ministerio Público 8.2 por ciento fueron reportados a la delegación o municipio y 3.8 por ciento notificadas a agencias de seguridad pública.

De la misma forma, menos de dos de cada cien casos de violación o intento de violación ocurridos durante el último año por parte de un familiar (1.7 por ciento) o en un contexto educativo (1.2 por ciento) fueron denunciados ante el Ministerio Público. En el caso del contexto laboral, sólo por 3.8 de cada mil violaciones se abrió una averiguación previa durante 2016. Para los eventos circunscritos al ámbito escolar, la mayoría de las mujeres del reducido número que interpuso una queja o denuncia a lo largo de su vida (6.4 por ciento), denunció ante las autoridades escolares (tres por ciento) la violación y/o el intento de violación.

La Tabla 5 presenta dos modelos de regresión logística que examinan las variables asociadas a la búsqueda de ayuda y la denuncia o interposición de una queja por violación y/o intento de violación en el último año. Los resultados deben ser interpretados con cautela debido al reducido número de casos. Hay pocas variables asociadas a la búsqueda de ayuda en alguna institución pública, privada y no gubernamental. A medida que incrementa la edad de la mujer el riesgo relativo de buscar ayuda por violación y/o intento de violación (disminuye en uno por ciento por cada año adicional). En cambio, el riesgo relativo de buscar ayuda se incrementa en seis por ciento por cada año adicional de escolaridad de la mujer. Las mujeres que hablan una lengua indígena tienen un riesgo relativo 56 por ciento menor de acudir a buscar ayuda que las que no hablan una lengua indígena. De forma similar las mujeres más desfavorecidas económicamente tienen una menor probabilidad de buscar ayuda ( 55 por ciento menor) que las mujeres de estrato socioeconómico alto. La fortaleza del apoyo recibido por parte de las redes sociales de las mujeres y ser receptora del programa de transferencias condicionadas Prospera también explica que las mujeres busquen ayuda. Finalmente, la variable con mayor poder predictivo es que la violación y/o el intento de violación se haya producido en el contexto comunitario o público. El riesgo relativo de buscar ayuda se incrementa en 60 por ciento cuando el evento se produce en el contexto o ámbito comunitario, en comparación con las acontecidas en otros contextos.

El segundo modelo de la Tabla 5 examina las variables asociadas a la denuncia de violación y/o intento de violación en el último año. En este modelo emergen menos variables estadísticamente significativas. Las mujeres que acuden a la escuela tienen un riesgo relativo 68 por ciento mayor que las que no acuden de haber puesto una denuncia o interpuesto una queja. 
Tabla 5: Modelos de regresión logística multivariados de variables asociadas a la búsqueda de ayuda por violación o intento de violación en el último año y denuncia

\begin{tabular}{lcc}
\hline & $\begin{array}{c}\text { Modelo } 1^{\mathrm{a}} \\
\text { Búsqueda de ayuda } \\
\mathrm{e}^{\beta}\end{array}$ & $\begin{array}{c}\text { Modelo } 2^{\mathrm{b}} \\
\text { Denuncia } \\
\mathrm{e}^{\beta}\end{array}$ \\
\hline Intercepto & $-2.59 * *$ & $-3.27 * *$ \\
Estado conyugal (casada) & 0.81 & 0.68 \\
Soltera & 0.71 & 1.20 \\
Separada, divorciada o viuda & $0.99 *$ & $0.98 \dagger$ \\
Edad & $1.06 *$ & 1.05 \\
Años de escolaridad & $0.44 \dagger$ & 1.45 \\
Habla lengua indígena & & \\
Estrato socioeconómico (alto) & $0.55 \dagger$ & 1.54 \\
Muy bajo & $0.55 *$ & 1.89 \\
Bajo & 0.72 & 3.34 \\
Medio & 1.04 & 0.91 \\
Empleada & $1.66 *$ & $2.70 \dagger$ \\
Receptora de Prospera & 0.99 & 0.79 \\
Reside contexto urbano (rural) & 0.76 & $1.68 * *$ \\
Asiste a la escuela & 0.96 & 1.07 \\
Número de personas en el hogar & 1.98 & 0.87 \\
Índice de roles de género & & $3.95 *$ \\
Violación o intento de violación & $1.60 * *$ & 0.96 \\
ámbito comunitario & $1.22 * * *$ & 545.86 \\
Fortaleza redes sociales & 1001.12 & \\
-2Log Likelihood & & \\
\hline No C & & \\
\hline
\end{tabular}

Nota: Categorías de referencia en paréntesis. ${ }^{a} 193$ mujeres indicaron que buscaron ayuda tras el evento de violación o intento de violación ocurrido en el último año, 900 mujeres indicaron que no lo hicieron. ${ }^{\text {a }} 75$ de las mujeres que indicaron buscar ayuda interpusieron una denuncia, 108 no lo hicieron.

*** $\mathrm{p}<0.0001 ; * * \mathrm{p}<0.001$, $\mathrm{p}<0.05 ;$ † $\mathrm{p}<0.10$

Fuente: elaboración propia a partir de la ENDIREH 2016.

De forma semejante, cuando ocurrió en el contexto público o comunitario, el riesgo relativo de interponer una queja o denuncia se incrementa en 295 por ciento. También los datos apuntan a que las mujeres que reciben Prospera tienden a presentar en mayor medida denuncias o quejas que las no receptoras. La explicación subyacente deberá ser examinada en futuras 
Violación e intento de violación de mujeres, patrones de búsqueda de ayuda y denuncia. Un análisis a partir ... /S. FRÍAS

investigaciones que probablemente tengan en cuenta el rol de los servicios de salud.

\section{LOS MOTIVOS POR LOS QUE LAS MUJERES NO BUSCAN AYUDA ANTE SITUACIONES DE VIOLACIÓN Y/O INTENTO DE VIOLACIÓN NO DE PAREJA}

Los motivos por los que las mujeres no buscan ayuda ante una situación de violación o intento de violación se examinan en la Tabla 6. Los datos se refieren a las experiencias acontecidas alguna vez en la vida en un contexto de relación escolar, laboral y comunitario, en el caso del contexto familiar los datos hacen referencia a los últimos 12 meses porque este es el único periodo temporal examinado por la ENDIREH 2016. Los porcentajes no suman 100 por ciento porque las mujeres pudieron proporcionar más de una opción de respuesta. En estas secciones de la ENDIREH 2016 se pregunta en global por los motivos por los que no acudió a buscar ayuda o denunció, pero los datos que se presentan en la Tabla 6 están filtrados para aquellas que padecieron violación y/o intento de violación. Por la severidad y trauma de este tipo de victimización, muy probablemente las mujeres estén refiriendo su respuesta a estos eventos.

El miedo a las consecuencias o por amenazas emerge como el principal motivo por el que las mujeres no buscan ayuda o no denuncian la violación y/o intento de violación. Por ejemplo, 41.9 por ciento de las mujeres que han padecido estas situaciones alguna vez en su vida en un contexto de relación laboral y 35.9 por ciento de las que las padecieron en un contexto familiar no buscaron ayuda por miedo a las consecuencias o por amenazas. Los sentimientos de vergüenza son el segundo principal motivo por el que las mujeres no acuden a buscar ayuda. Tres de cada diez mujeres violadas o que padeció un intento en un contexto educativo, y casi cuatro de cada diez que lo sufrieron en un contexto familiar indicaron que los sentimientos de vergüenza impidieron que buscara ayuda. Destaca el hecho de que un porcentaje considerable de mujeres (entre 16.3 y 31.4 por ciento, dependiendo del contexto de relación) indicara que no acudió a buscar ayuda porque no le iban a creer.

Porcentajes menores, pero nada desdeñables de mujeres, adujeron motivos vinculados con las autoridades públicas y conocimiento sobre los procesos de denuncia. 29.5 por ciento de las mujeres que no buscaron ayuda por situaciones de violación o intento de violación en un contexto de relación laboral indicaron que no sabían cómo o donde denunciar. Lo mismo sucede en contextos comunitarios, familiares y escolares (respectivamente, $19.4,17.4$ y 16.7 por ciento). 


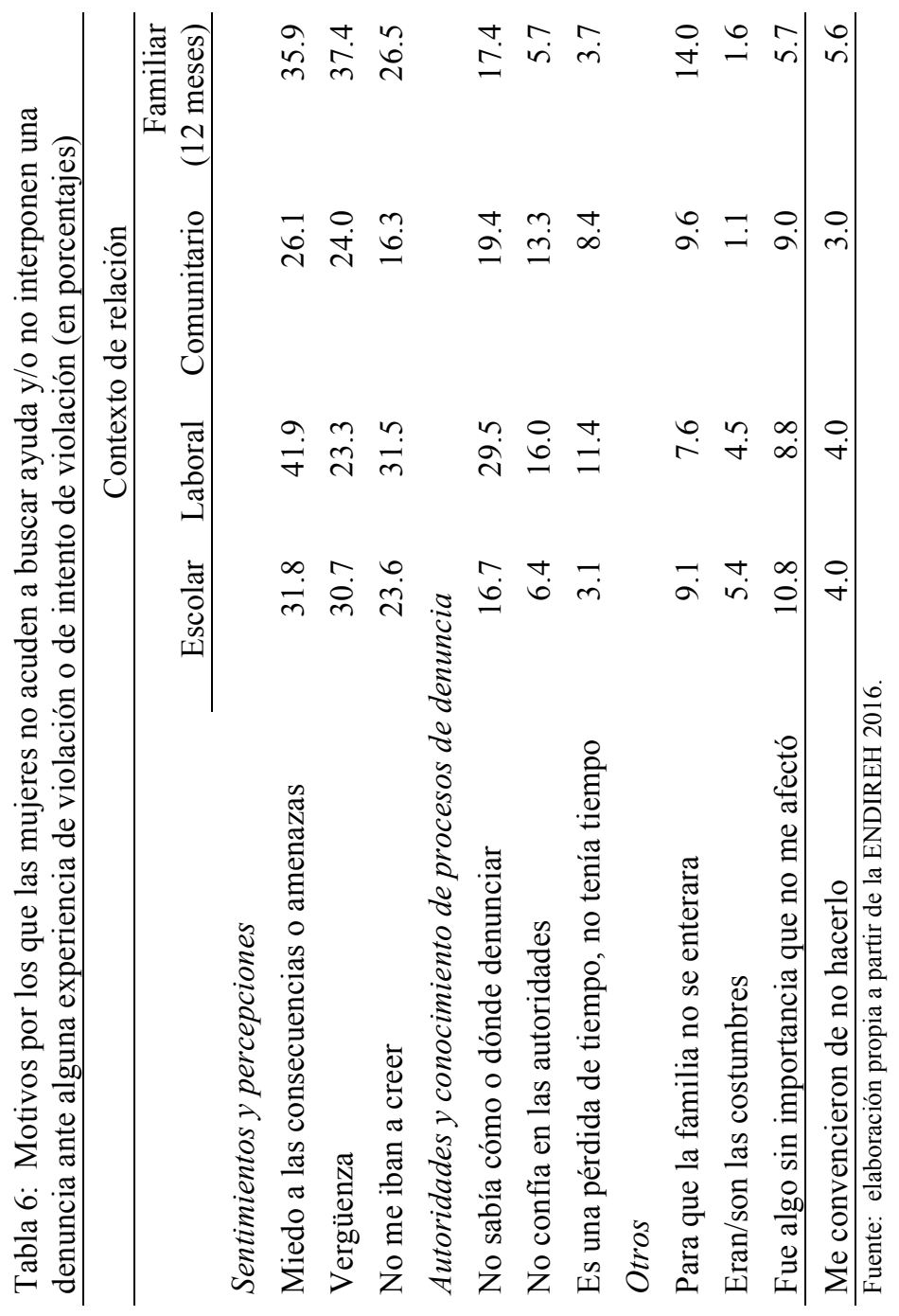


Las mujeres desconfían de las autoridades, y por ese motivo 13.3 por ciento de las mujeres objeto de violación y/o intento de violación en el espacio público o comunitario y 16 por ciento de las que lo fueron en un contexto laboral no buscó ayuda o no denunció. En este último contexto de relación, poco más de una de cada diez mujeres indicó que no denunciar o buscar ayuda porque "es una pérdida de tiempo". Estos últimos motivos suscitan preguntas sobre las acciones y omisiones de los poderes públicos.

Las mujeres también reportaron otros motivos. 14 por ciento de las mujeres objeto de violación y/o de un intento de violación por un familiar y nueve por ciento de las que lo padeció en un contexto de relación escolar o comunitario no buscaron ayuda para que su familia no se enterara. Existe cierta minimización o normalización de la violencia padecida, ya que algunas mujeres señalaron que "eran/son las costumbres"; entre seis y once por ciento, dependiendo del contexto de relación, indicó que se trató de algo sin importancia que no le afectó. Finalmente, en menor medida algunas mujeres indican que no acudieron a buscar ayuda y/o no interpusieron una denuncia porque las convencieron de no hacerlo. Este es el caso, por ejemplo, de 5.6 por ciento de las mujeres objeto de violación y/o intento de violación por un familiar en el último año.

\section{Conclusiones}

La ENDIREH 2016 muestra que casi seis de cada cien mujeres mexicanas han padecido un intento de violación alguna vez en su vida y 4.4 por ciento han sido violadas por parte de una persona distinta a la pareja romántica. En general, a 7.8 por ciento de las mujeres mexicanas las han violado o han intentado hacerlo a lo largo de su vida. La cifra a la que aproximadamente equivale este porcentaje (tres millones 560 mil mujeres) no deja lugar a dudas de la magnitud de la expresión más severa de violencia sexual no de pareja en contra de las mujeres. Si contempláramos la violación en el seno de una relación de pareja por parte de la actual o última pareja, la cifra incrementaría ya que 3.6 por ciento de las mujeres (un millón 540 mil) reveló haber sido violada por su actual pareja o expareja. De entre éstas, poco más de tres de cada diez (31.6 por ciento) además de ser violada por su actual o última pareja ha padecido una violación o un intento de violación en algún momento de su vida.

Las cifras que proporciona la ENDIREH 2016 son conservadoras ya que, debido a factores individuales como el deseo de privacidad, la vergüenza, deseabilidad social y estigmatización del abuso sexual es posible que algunas mujeres hayan proporcionado una falsa respuesta negativa. 
Por ejemplo, en el caso concreto de mujeres indígenas, estudios previos han mostrado que tienden a responder adecuadamente los cuestionarios como los de la ENDIREH, debido al monolingüismo, desconfianza o a otras causas (Huacuz Elías y Rosas Vargas, 2011). Asimismo, algunos aspectos metodológicos como la correspondencia entre las definiciones conceptuales y operativas en el cuestionario, la forma de administración del mismo, y dudas sobre la confidencialidad de la información pueden estar detrás del bajo reporte (detalles en Frías, 2017). A pesar de estas limitaciones, la ENDIREH 2016 es la mejor fuente de datos para medir el fenómeno. La magnitud de la violación por una persona distinta a la pareja examinada a partir de la ENDIREH 2016 es 3.5 veces mayor a la que arroja la ENDIREH 2011. Esto, asociado a que el cuestionario de 2016 ubica a la mujer en contextos de relación específicas.

Las niñas y adolescentes menores de 15 años están en una situación de gran riesgo. La incidencia de violación o intentos de violación antes de los 15 años es mucho mayor que la reportada por las mujeres después de esa edad. 2.9 por ciento de las mujeres indicó ser violada antes de los 15 años y cuatro por ciento indicó que había sufrido un intento de violación. En total, 5.1 por ciento padeció una u otra experiencia. Después de los 15 años las cifras son, respectivamente, 2.4 y 2.8 por ciento. Las personas agresoras tienden a ser personas del círculo familiar, lo que implica que han podido tener acceso recurrente a las mujeres cuando eran niñas o adolescentes.

La infancia y adolescencia es clave en el desarrollo del individuo y en su vida adulta. La victimización durante esta etapa de la vida tiene serias consecuencias sobre la salud física y mental de las personas. Sólo por mencionar algunos, desórdenes alimenticios, (Unikel-Santoncini et al., 2011), consumo de drogas (Ramos-Lira et al., 1998), infecciones de transmisión sexual embarazo infantil o adolescente. Con respecto a este último punto, de acuerdo con las estadísticas de natalidad que publica INEGI, en 2016 se registraron 8203 nacimientos ocurridos desde 2010 en México de madres jóvenes de 14 años y menos ${ }^{3}$ (cálculos propios), parte de los cuales pueden ser fruto de una violación. Por lo tanto, estamos antes una problemática que requiere acciones específicas de prevención y atención para este grupo etario. Esto porque, como muestra el presente estudio, 7.3 por ciento de las mujeres a quienes las violaron o intentaron violarlas antes de los 15 años, tuvieron una experiencia similar en el último año, comparado con 0.6 por

${ }^{3} 84$ por ciento de éstos ocurrieron durante 2016. El resto, ocurrieron entre 2010 y 2015, pero no fueron registrados hasta 2016. 
ciento de las mujeres que no tuvieron esas experiencias antes de los 15 años, lo cual sugiere un patrón de revictimización sexual.

Las mujeres viven en silencio las experiencias de violación y/o intento de violación, sobre todo aquellas que ocurren en un contexto de relación laboral y familiar. Aunque le comuniquen a alguien de su círculo social, esto no implica que acudan a buscar ayuda a alguna institución pública o privada. La experiencia de buscar ayuda está atravesada por quien es la persona generadora de la agresión. Sólo 4.4 por ciento de las mujeres que fueron objeto de violación y/o intento de violación en el último año buscó algún tipo de ayuda, en el contexto de relación laboral. En el ámbito público o comunitario, sólo 16.4 por ciento buscó ayuda por las agresiones. La búsqueda de ayuda no implica tampoco que se interponga alguna queja o denuncia. Las situaciones acaecidas en el ámbito público o privado son denunciadas en mayor medida (13 por ciento) que las ocurridas en el contexto familiar (2.9 por ciento) o escolar (2.3 por ciento). Los proveedores de servicios e instituciones públicas deben monitorear la probable ocurrencia de violaciones o intentos de violación en estos contextos de relación para poder ofrecer servicios a las víctimas y realizar acciones que prevención.

Resumiendo, en el último año, sólo dos de cada diez mujeres objeto de violación y/o intento de violación buscó ayuda, y sólo 8.4 por ciento de estas agresiones sexuales fue objeto de denuncia o queja, no todas ellas ante el Ministerio Público, autoridad competente para iniciar el proceso de procuración de justicia. Este dato sugiere que los datos de incidencia delictiva que proporcionan las autoridades de procuración de justicia sólo reflejan la punta del iceberg de la problemática, y que tienden a referirse a las violaciones e intentos de violación que ocurren en el ámbito público o comunitario. Este potencial contraste entre las cifras de las encuestas y los registros administrativos apunta a que la violencia en contra de las mujeres, en general, y la violación, en particular, debe estudiarse a partir de las encuestas probabilísticas sobre violencia contra las mujeres.

Es probable que las mujeres objeto de violación o de intento de violación recurrieran a otras fuentes de apoyo informal que no son exploradas por la ENDIREH 2016, o bien que su estrategia de afrontamiento tuviera un carácter más pasivo que activo, o que todavía no hubieran conceptualizado su experiencia como una violación (Kahn et al., 2003; Fisher, 2009; LeMaire et al., 2016). Este último punto parece estar apoyado por los datos de la ENDIREH 2016 ya que, al igual que investigaciones previas (Kaukinen, 2002; Kogan, 2004), un porcentaje menor de violaciones perpetradas por conocidos y familiares que las perpetradas por personas desconocidas 
o en el ámbito público se reporta a las autoridades. Probablemente, las mujeres tengan mayores dificultades en catalogar como violación los abusos de amigos o conocidos.

El análisis bivariado muestra que algunos grupos de mujeres reportaron, en mayor medida que otros, haber sido víctimas de una violación y/o de intento de violación. Este es el caso, por ejemplo, de las mujeres con menor escolaridad, las que hablan una lengua indígena y las de estrato socioeconómico bajo y muy bajo. Estos hallazgos sugieren que las experiencias de violencia en contra de las mujeres, que conllevan a la violación, deben entenderse teniendo en cuenta una perspectiva de género interseccional (Crenshaw, 1991; Collins, 2000; Curiel, 2007) ya que el ser mujer adquiere implicaciones distintas dependiendo de la posición de la mujer en las distintas estructuras de estratificación. ${ }^{4}$

Los sentimientos de vergüenza y miedo impiden a muchas mujeres acercarse a las autoridades. Estos sentimientos están socialmente construidos, a partir de los significados atribuidos al sexo, la sexualidad y el valor de éstos en la vida de una mujer y para para su familia. Algunos sectores sociales consideran que las mujeres deben cuidarse, protegerse y no exponerse. En este sentido, la violación es el castigo por no hacerlo (Vance, 1992; Weiss, 2010). Los deseos de privacidad y el miedo también son factores que median en la búsqueda de ayuda. Es relevante que algunas mujeres no sepan que pueden denunciar o cómo hacerlo. Este dato apunta a que deben revisarse las políticas de identificación y difusión sobre instituciones a las que las víctimas de violencia género pueden acudir a buscar ayuda. Éstas, han tendido a centrarse en la violencia de pareja, descuidando otras expresiones de violencia de género como la violación o el acoso u hostigamiento sexual en distintos ámbitos, sólo por mencionar algunas.

Tampoco es desdeñable, por las implicaciones que tiene en términos de mejora de los servicios públicos, la cantidad de mujeres que no acuden a las autoridades porque no confía en ellas o porque cree que es una pérdida de tiempo. Si bien investigaciones realizadas en otros países muestran que muchas mujeres no acuden a las autoridades porque temen que por la naturaleza del delito - carácter sexual — sean revictimizadas y culpadas por las autoridades (Weiss, 2010; Murphy et al., 2014), en el caso de

\footnotetext{
${ }^{4}$ Para la perspectiva feminista interseccional los distintos sistemas de dominación/opresión como por ejemplo sistemas raciales/étnicos, sistemas de clase, sistema sexual, así como el patriarcado contribuyen a explicar la violencia en la vida de las mujeres. Para esta perspectiva, "no hay una explicación o teoría capaz de explicar [las múltiples formas de] la violencia en contra de las mujeres. De hecho, la explicación o teoría debe variar de acuerdo con la interacción de las distintas formas de opresión que experimentan las mujeres a lo largo de su vida, y éstas estarán relacionadas con situaciones históricas, sociales y culturales concretas" (Damant et al., 2008: 123-133).
} 
México se le debe añadir la desconfianza generalizada en las instancias de procuración de justicia. De acuerdo con los datos de la ENVIPE 2016, 49 por ciento de la población de México no confía en el Ministerio Público o a las Procuradurías (cálculos propios). Si las personas no tienen confianza en las autoridades, es poco probable que acudan a pedir ayuda. En el caso de un delito altamente estigmatizado como la violación, la probabilidad es todavía menor. Esto acaba socavando sus posibilidades de acceso a la justicia, entendida como la posibilidad de conseguir una reparación justa y oportuna del agravio de acuerdo con el marco normativo legal local, nacional e internacional.

A pesar de los hallazgos tan relevantes que se desprenden de esta investigación, es preciso apuntar varias limitaciones. La más importante es la vinculada con el uso de datos secundarios. Algunos ejemplos incluyen, que la ENDIREH 2016 no recaba datos sobre violencia y abuso sexual en la familia después de los 15 años, que las categorías de respuesta para personas perpetradoras no permitan diferenciar entre varones y mujeres (ej. padrastro/madrastra), que actos constitutivos de violación como la introducción de objetos o dedos la vagina u orificio anal o no se especifiquen, que no se examinan los patrones de búsqueda de ayuda por eventos de abuso sexual acontecidos antes de los 15 años y el circunscribir las opciones de respuesta a sí o no sin proporcionar las opciones de quizás o no lo sé. Desde la academia como desde las instancias impulsoras de encuestas sobre victimización y violencia en contra de las mujeres se debe profundizar, como ha sucedido en otros países (ver por ejemplo Bachman, 2000; Walby y Myhill, 2001; Fisher, 2009), en el debate teórico ni metodológico sobre cómo se deberían estudiar las experiencias de violación de mujeres, en términos de los diseños de investigación, definiciones operativas, y las implicaciones tras la redacción de los reactivos de las encuestas. Futuros estudios deben examinar con detalle cuál es el trato que reciben las mujeres objeto de violación o de intento de violación cuando van a pedir ayuda o interponen una queja, así como cuál es el resultado de ésta.

Esta investigación tiene diversas implicaciones de políticas públicas. Se necesitan reforzar los esfuerzos para prevenir, atender y sancionar la violencia sexual en contra de las niñas y adolescentes, quienes con frecuencia quedan excluidas o desdibujadas en las acciones públicas sobre violencia en contra de las mujeres. Adicionalmente, el reducido porcentaje de mujeres que acude a buscar ayuda tras una violación o intento de violación, apunta a la necesidad de que las distintas instituciones que, por mandato de la Ley General de Acceso de las Mujeres a una Vida Libre de Violencia y 
sus homólogas en las entidades federativas, deben atender la violencia de género en contra de las mujeres establezcan mecanismos de difusión para la población en general. El objetivo de estas campañas podría ser alentar a las víctimas para que acudan a buscar ayuda, sobre todo ayuda médica por las distintas consecuencias que una violación y/o un intento puede tener sobre la salud física y mental. Adicionalmente se deben realizar esfuerzos para eliminar las barreras asociadas a la no búsqueda de ayuda, especialmente aquellas asociadas al desconocimiento de los procedimientos de denuncia, las prácticas y disfunciones institucionales que hacen que las personas no crean en las instituciones, así como a las experiencias subjetivas como el miedo, la vergüenza, el temor a no ser creído y la estigmatización. Estas últimas pueden estar al mismo tiempo vinculadas con falsas respuestas negativas al cuestionario de la ENDIREH 2016.

Aunque la violación y el intento de violación son las formas más extremas de violencia sexual en contra de las mujeres, la prevención de éstas debe englobar las formas menores de violencia sexual en contra de las mujeres. Es preciso enfatizar que estas formas menores de violencia sexual, como los tocamientos, manoseos, actos exhibicionistas, tienden a estar en cierta medida - tolerados y minimizados, ya que son parte del continuo de violencia sexual en contra de las mujeres (Kelly 1987). Su tolerancia, no obstante, favorece la existencia de la violación y el intento de violación. Hasta que, como sociedad, no visibilicemos la violación y/o intento de violación como parte de este continuo, miles de niñas y mujeres mexicanas las continuaremos padeciendo año tras año.

\section{REFERENCIAS BIBLIOGRÁFICAS}

Bachman, R., 2000, "A Comparison of Annual Incidence Rates and Contextual Characteristics of Intimate Partner Violence Against Women from the National Crime Victimization Survey and the National Violence Against Women Survey", en Violence Against Women 6(8), 839-867.

Barrett, B. J. y Pierre, M. St., 2011, "Variation in Women's Help Seeking in Response to Intimate Partner Violence: Findings from a Canadian Population-Based Study", en Violence Against Women 17(1), 47-70.

Borges, G., Benjet, C., Medina-Mora, M. E., Orozco, R., Molnar, B. E. y Nock, M. K. 2008, "Traumatic events and suicide-related outcomes among Mexico City adolescents", en Journal of_Child Psychology \& Psychiatry 49(6), 654-666.

Burgess, A. W. y Carretta, C. M., 2016, "Rape and Its Impact on the Victim", en Hazelwood, R. R. and Burgess, A. W., Practical aspects of rape investigation: A multidisciplinary approach, Taylor and Francis. Boca Raton. 
Campbell, R., 1998, “The community response to rape: victims' experiences with the legal, medical and mental health systems", en American Journal of Community Psychology 26, 355-379.

Casique, I., 2006, “¿Cuándo puedo decir no? empoderamiento femenino y sexo no deseado en México", en Papeles de Población 21(1), 49-81.

Casique, I. y Castro, R., 2012, “Análisis comparativo de prevalencia de las violencias de pareja, y principales variables asociadas", en Casique, I. y Castro, R. (coords.), Retratos de la Violencia contra las Mujeres en México, pp.145-214, CRIM-UNAM, Cuernavaca.

Casique, I. y Castro, R. (eds.), 2014, Expresiones y contextos de la violencia contra las mujeres en México. Análisis comparativo de la ENDIREH 2011, Cuernavaca, CRIM-UNAM.

Castro, R. y Erviti, J., 2003, “ Violación de derechos reproductivos durante la atención institucional del parto: un estudio introductorio", en López, P., Rico, B., Langer, A. y Espinoza, G., Género y Política en Salud, pp. 255-273, México DF, UNIFEM.

Chavez Ayala, R., Rivera-Rivera, L., Ángeles-Llerenas, A., Díaz-Cerón, E., Allen, B. y Lazcano-Ponce, E., 2009, "Factores del abuso sexual en la niñez y la adolescencia en estudiantes de Morelos, México”, en Rev. Sáude Publica, 43(3), 506514.

Collins, P. H., 2000, Black Feminist Thought: Knowledge, Consciousness and the Politics of Empowerment. New York, Routledge.

Crenshaw, K. W.,1991, "Mapping the margins: intersectionality, identity politics, and violence against women of color", en Stanford Law Review 43(6), 1241-1299.

Crowell, N. A. y Burgess, A. W., (eds.), 1996, Understanding Violence against women, Washington, D.C., National Academy Press.

Curiel, O., 2007, “Los Aportes de las afrodescendientes a la teoría y la práctica feminista. desuniversalizando el sujeto "mujeres", en Femenías, M. L. y Vasallo Barrueta, N., Perfiles del Feminismo Iberoamericano, Buenos Aires, Catálogos.

Damant, D., Lapierre, S., Kouraga, A., Fortin, A., Hamelin-Brabant, L., Lavergne C. y Lessard, G., 2008, "Taking child abuse and mothering into account: intersectional feminism as an alternative for the study of domestic violence", en Affilia 23(2), 123-133.

Douglas, E. M. y Hines, D. A., 2011, “The helpseeking experiences of men who sustain intimate partner violence: an overlooked population and implications for practice", en Journal of Family Violence, 26(6), 473-485.

Echarri, C. J., 2008, “Desigualdad socioeconómica y salud reproductiva: una propuesta de estratificación social aplicable a las encuestas", en Lerner, S. y Szasz, I., Salud Reproductiva y Condiciones de Vida en México, pp 59-113, México, El Colegio de México. 
Fanslow, J. L. y Robinson, E. M., 2010, "Help-seeking behaviors and reasons for help seeking reported by a representative sample of women victims of intimate partner violence in New Zealand", en Journal of Interpersonal Violence, 25(5), 929-951.

Fernández Rodríguez de Liévana, G., 2015, "Los estereotipos de género en los procedimientos judiciales por violencia de género: el papel del comité CEDAW en la eliminación de la discriminación y de la estereotipación", en Oñati Socio-Legal Series, 5(2), 498-519.

Fileborn, B., 2013, "Conceptual understandings and prevalence of sexual harassment and street harassment", en Australian Centre for the Study of Sexual Assault, Melbourne ACSSA.

Fisher, B. S., 2009, "The effects of survey question wording on rape estimates: evidence from a quasi-experimental design", en Violence Against Women, 15(2), 133-147.

Fisher, B. S., Daigle, L. E., Cullen, F. T. y Turner, M. G., 2003, "Reporting sexual victimization to the police and others: results from a national-level study of college women", en Criminal Justice and Behavior, 30(6), 6-38.

Fontes, L. A., 2007, "Sin vergüenza: addressing shame with latino victims of sexual abuse and their families", en Journal of Child Sexual Abuse, 16(1), 61-83.

Fontes, L. A. y Plummer, C., 2010, "Cultural issues in disclosures of child sexual abuse", en Journal of Child Sexual Abuse, 19(5), 491-518.

Frías, S. M., 2012, "Violencia contra las mujeres mexicanas en los ámbitos familiar, educativo, laboral, comunitario e institucional: evidencia a partir de las encuestas", en Ríquer, F. y Castro, R. (coords), Estudio Nacional sobre las Fuentes, Orígenes y Factores que Reproducen la Violencia contra las Mujeres., México, CONAVIM. Disponible en http://www.conavim.gob.mx/es/CONAVIM/Estudio_ sobre_las_Fuentes.

Frías, S. M., 2013, "Definiciones, género y acoso sexual en el ámbito laboral: el caso de un tribunal federal mexicano", en Agoff, C., Casique, I. y Castro, R., Visible en Todas Partes. Estudios sobre Violencias Contra las Mujeres en Múltiples Ámbitos, pp. 75-102, Cuernavaca, CRIM-UNAM/Porrúa.

Frías, S. M., 2013, "Strategies and help-seeking behavior in law-enforcement offices among mexican women experiencing partner violence", en Violence Against Women, 19(1), 24-49.

Frías, S. M., 2014, "Ámbitos y formas de violencia contra las mujeres y niñas: evidencia a partir de las encuestas", en Acta Sociológica, 65, pp. 11-36.

Frías, S. M., 2017, "25 Años de investigación cualitativa y cuantitativa sobre violencia hacia las mujeres en México", en Realidad, Datos y Espacio. Revista Internacional de Estadística y Geografia, 8(2): 4-51.

Frías, S. M., 2017, "El género en la violencia y la violencia de género hacia las mujeres mexicanas. Discusiones conceptuales y metodológicas", en Cerva, D., 
Varias miradas, distintos enfoques: los estudios de género a debate, pp. 107-140, Cuernavaca, UAEM.

Frías, S. M. y Agoff, C., 2015, "Between support and vulnerability: examining family support among women victims of intimate partner violence in Mexico", en Journal of Family Violence 30(3), 277-291.

Frías, S. M. y Erviti, J., 2014, "Gendered experiences of sexual abuse of teenagers and adolescents in Mexico", en Child Abuse and Neglect 38(14): 776-787.

Frías, S. M. y Ríos, A., 2017, “After rape. Mexican women's help seeking and access to health in public prosecutor's offices", en Feminist Crimininology.

Gasman, N., Villa Torres, L., Moreno, C., y Billings, D. L., 2006, "Violencia sexual en México", en Lozano Ascencio, R., Del Rio Zolezzi, A., Azaola Garrido, E. et al., Informe Nacional sobre Violencia y Salud, pp.167-204, Mexico, Secretaría de Salud/ UNIFEM.

Gaytan Sánchez, A. P., 2009, “El Acoso sexual en lugares públicos: un estudio desde la grounded theory", en El Cotidiano, 143: 5-17.

González-Fortaleza, C., Ramos-Lira, L., L. Vignau Brambila, E. y Ramírez Villarreal, C., 2001, "El abuso sexual y el intento suicida asociados con el malestar depresivo y la ideación suicida de los adolescentes", en Salud Mental, 24(6), 16-25.

Hay, C.,2005, "Whether to ignore them and spin: moral obligations to resist sexual harassment", en Hypatia, 20(4), 94-108.

Huacuz Elías, M. G. y Rosas Vargas, R., 2011, "Violencia de género y mujeres indígenas en el Estado de Michoacán”, en Rosas Vargas, R., El camino y la voz. Visiones y perspectivas de la situación actual de Michoacán: género, política, arte y literatura, pp. 11-112, Guanajuato, Universidad de Guanajuato y Altres CostaAMIC Editores.

Kahn, A. S., Jackson, J., Kully, C., Badger, K. y Halvorsen, J., 2003, “Calling it rape: differences in experiences of women who do or do not label their sexual assault as rape", en Psychology of Women Quarterly, 27, 233-242.

Kaukinen, C.,2002, "The help-seeking of women violent crime victims: findings from the Canadian violence against violence women survey", en International Journal of Sociology and Social Policy, 22(7/8), 5-44.

Kavanaugh, P. R., 2012, “The continuum of sexual violence: women's accounts of victimization in urban nightlife", en Feminist Crimininology, 8(1), 20-39.

Kelly, L.,1987, “The continuum of sexual violence”, en Holmes, J. y Maynard, M., Women, Violence and Social Control (pp. 46-60), London, MacMillan.

Kogan, S., 2004, "Disclosing unwanted sexual experiences: results from a national sample of adolescent women", en Child Abuse \& Neglect, 28, 147-165.

Koss, M. P., Heise, L. y Russo, N. F., 1994, "The global health burden of rape", en Psychology of Women Quarterly, 18, 508-537. 
Kruttschnitt, C., Kalsbeek, W. D. y House, C. C., (eds.), 2014, Estimating the incidence of rape and sexual assault, Washington, D.C., The National Academies Press.

Kubiak, S. P., Nnwulezi, N., Karim, N., Sullivan, C. M. y Beeble, M. L., 2012, "Examining disclosure of physical and sexual victimization by method in samples of women involved in the criminal justice system", en Journal of Offender Rehabilitation, 51(3),161-175.

LeMaire, K. L., Oswald, D. L. y Russell, B. L., 2016, "Labeling sexual victimization experiences: the role of sexism, rape myth acceptance, and tolerance for sexual harassment", en Violence and Victims, 31(2), 332-346.

Liang, B., L. Goodman, A., Tummala-Narra, P. y Weintraub, S., 2005, “A theoretical framework for understanding help-seeking processes among survivors of intimate partner violence", en American Journal of Community Psychology, 36(12), 71-84.

MacKinnon, C. A., 1979, Sexual harassment of working women: a case of sex discrimination, New Haven, Yale University Press.

MacKinnon, C. A., 1989, Toward a feminist theory of the state, Cambridge, MA, Harvard University Press.

Maier, S. L., 2008, ''I have heard horrible stories...' rape victims advocates' perceptions of the revictimization of rape victims by the police and the medical system “, en Violence Against Women, 14(7),786-808.

McNair, L. D. y H. A. Neville., 2010, "African American Women Survivors of Sexual Assault: The Intersection of Race and Class", en Women and Therapy, 18(3-4),107-118.

Medina-Mora, M. E., Borges-Guimaraes, G., Lara, C., Ramos-Lira, L., Zambrano, J. y Fleiz-Bautista, C., 2005, "Prevalencia de sucesos violentos y de trastorno por estrés postraumático en la población mexicana", en Salud Pública de México, 47(1), 8-22.

Menard, K. S., 2005, Reporting sexual assault: a social ecology perspective, New York, LFB Scholarly Publications.

Muganyizi, P. S., Nyström, L., Axemo, P. y Emmelin, M., 2011, "Managing in the Contemporary world: rape victims' and supporters' experiences of barriers within the police and the health care system in Tanzania", en Journal of Interpersonal Violence, en 26(16), 3187-3209.

Murphy, S. B., Edwards, K. M., Bennet, S., Bibeau, S. J. y Sichelstiel, J., 2014, "Police reporting practices for sexual assault cases in which "the victim does not wish to pursue charges", en Journal of Interpersonal Violence, 29(1), 144-156.

Oláiz, G., Rico, B. y del Río, A., 2003, Encuesta Nacional sobre Violencia contra las Mujeres. México, Instituto Nacional de Salud Pública. 
Oláiz, G., Rojas, R., Valdez-Santiago, R., Franco, A. y Palma, O., 2006, "Prevalencia de diferentes tipos de violencia en usuarias del sector salud en México", en Salud Pública de México 48(Suppl 2), S232-S238.

Oláiz, G., Uribe, P. y Del Rio Zolezzi, A., 2009, Encuesta Nacional sobre Violencia contra las Mujeres 2006. México, Centro Nacional de Equidad de Género y Salud Reproductiva, Secretaría de Salud.

Peterson, Z. D. y Muehlenhard, C. L., 2011, "A match-and-motivation model of how women label their nonconsensual sexual experiences", en Sychology of Women Quarterly, 35(4), 558-570.

Phipps, A., 2009, "Rape and respectability: ideas about sexual violence and social class", en Sociology, 43(4), 667-683.

Ramos-Lira, L., Koss, M. P. y Russo, N. F., 1999, “Mexican American women's definitions of rape and sexual abuse", en Hispanic Journal of Behavioral Sciences, 21(3), 236-265.

Ramos-Lira, L., Saldívar Hernández, G., Medina-Mora, M. E., Rojas-Guiot, E. y Villatoro-Velázquez, J., 1998, "Prevalencia de abuso sexual en estudiantes y su relación con el consumo de drogas", en Salud Pública de México, 40(3), 221-233.

Ramos-Lira, L., Saltijeral-Méndez, M. T., Romero-Mendoza, M., CaballeroGutiérrez, M. Á. y Martínez-Velez, N. A., 2001, "Violencia sexual y problemas asociados en una muestra de usuarias de un centro de salud", en Salud Pública de México, 43(3), 182-191.

Rich, K. y Seffrin, P., 2012, "Police interviews of sexual assault reporters: do attitudes matter?", en Violence and Victims, 27(2), 263-279.

Rivera, L., Allen, B., Chávez, R. y Ávila, L., 2006, “Abuso físico y sexual durante la niñez y revictimización de las mujeres mexicanas durante la edad adulta", en Salud Pública de México 48(Supp1 2), S268-S278.

Rose, L. E., Campbell, J. y Kub, J., 2000, “The role of social support and family relationships in women's responses to battering", en Health Care for Women International, 21, 27-39.

Sabina, C., 2011, "Help-seeking in a national sample of victimized women: the influence of victimization types”, en Journal of Interpersonal Violence, 27(1), 4061.

Sabogal, F., Marín, G., Otero-Sabogal, R., Vanoss-Marín, B. y Perez-Stable, E. J., 1987, "Hispanic familism and acculturation: what changes and what doesn't", en Hispanic Journal of Behavioral Sciences, 9(4),397-412.

Stoltenborgh, M., 2011, “A global perspective on child sexual abuse: meta-analysis of prevalence around the world", en Child Maltreatment ,16(2), 79-101.

Thirsk, L., 2012, Law and the discursive construction of street harassment as violence in Mexico City. Toronto, Canada, CERLAC. York University. 
Ullman, S. E. y Filipas, H. H., 2001, "Correlates of formal and informal support seeking in sexual assault victims", en Journal of Interpersonal Violence, 16, 10281047.

Unikel-Santoncini, C., Ramos-Lira, L. y Juárez-García, F., 2011, “Asociación entre abuso sexual infantil y conducta alimentaria de riesgo en una muestra de adolescentes mexicanas", en Revista de Investigación Clínica, 63(5), 475-483.

Vance, C., 1992, Pleasure and danger: toward a politics of sexuality, en C. Vance, Pleasure and danger. Exploring female sexuality, London, Harper Collins Publishers.

Walby, S. y Myhill, A., 2001, "New survey methodologies in researching violence against women", en British Journal of Criminology, 41(3), 502-522.

Weiss, K. G., 2010, "Too ashamed to report: deconstructing the shame of sexual victimization", en Violence Against Women, 5(3), 286-310.

Zakar, R., Zakar, M. Z. y Krämer, A., 2012, "Voices of strenght and struggle: women's coping strategies against spousal violence in Pakistan", en Journal of Interpersonal Violence, 27(16), 3268-3298.

\section{RESUMEN CURRICULAR DE LA AUTORA}

\section{Sonia M. Frías}

Licenciada en Ciencias Políticas y de la Administración por la Universidad de Barcelona (1997) y Doctora en Sociología por la Universidad de Texas en Austin (2008). Investigadora titular del programa Violencia(s), Derechos y Salud, en el Centro Regional de Investigaciones Multidisciplinarias de la UNAM. Integrante del Sistema Nacional de Investigadores (Nivel II). Actualmente coordina el proyecto Diagnóstico Nacional sobre Violencias en contra de Mujeres y Niñas Indígenas de la Comisión Nacional de Desarrollo de los Pueblos Indígenas y el proyecto Victimización y Violencia en contra de los niños y adolescentes en México, financiado por el fondo mixto CONACYT-INEGI. Sus líneas de investigación versan sobre violencia de género en contra de las mujeres, violencia contra los niños/ as y adolescentes acceso a la justicia de víctimas de violencia de género e igualdad de género.

Dirección electrónica: sfrias@correo.crim.unam.mx

Artículo recibido el 26 de septiembre de 2016 y aprobado el 9 de octubre de 2017. 